\title{
TALVEN TUHOT HEDELMÄPUISSA JA MARJAPENSAISSA VUONNA 1947.
}

\author{
H. J. E. HÅRDH. \\ Maatalouskoelaitoksen kasvitautiosasto, Tikkurila.
}

Saapunut 13. I. 1948 .

Hedelmänviljely Suomessa on lähes säännöllisin väliajoin kärsinyt ankarien pakkastalvien johdosta. Tuhoisia talvia on viimeksi ollut vuosina 1915-1917, 1927-1929 ja 1939-1942 (4). Viimeksimainitun tuhokauden talvista oli vuosien 1939 - 1940 ankarin kahden seuraavan talven täydentäessä tuhoa. Tällöin kärsityistä vahingoista oli hedelmänviljelymme jo toipumassa, kun vuosien 1946-1947 talvi jälleen aiheutti hedelmä- ja marjatarhoissa vaurioita, joiden seuraukset paikoin olivat varsin tuhoisat. - Kun pakkasvioitukset Suomessa ovat tavalliset, ja niiden merkitys hedelmänviljelylle ensiarvoisen tärkeä, otettiin Maatalouskoelaitoksen kasvitautiosastolla talven 1946-1947 aiheuttamien vaurioiden ankaruus eri osissa maata sekä vaurioiden ilmenemismuodot ja syyt lähemmin selvitettäviksi.

Esitettävät tiedot perustuvat pääasiassa kuukausi-ilmoituksiin, joita Maatalouskoelaitoksen kasvitautiosaston tiedoittajina vuonna 1947 toimineet puutarhaneuvojat ovat osastolle lähettäneet. Säännöllisesti tiedoittavia, eri puolilla maata toimivia neuvojia on ollut 35. Sen lisäksi ovat puutarhaviljelijät kasvukauden aikana lähettäneet kasvitautiosastolle tietoja puutarhaa kohdanneista vahingoista kyselyjen muodossa. Tällaisia talven tuhoja koskevia ilmoituksia on kasvukauden aikana tullut 102 .

Kasvullisuuden herätessä eloon keväällä todettiin hedelmäpuiden ja marjapensaiden kehitys monin paikoin epänormaaliksi. Hedelmäpuiden lehtisilmut puhkesivat tavallista hitaammin, lehtien kehitys oli hidasta ja niiden yleisväri ruskehtava. Kukkasilmut, joita edellisenä syksynä oli havaittu muodostuvan runsaasti, puhkesivat joko kokonaan lehdettömissä puissa tai olivat lehdet kukkien auetessa pieniä, kooltaan usein vain $2-3 \mathrm{sm}$ läpimittaisia. Milloin vioitus oli kohdannut puuta ankarasti, saattoivat kukkasilmut jäädä kokonaan aukeamatta (kuva 1) tai kuihtuivat heti auettuaan. Lievemmissä tapauksissa kukat aukenivat normaalisti, mutta jäivät kooltaan tavallista pienemmiksi. Pahimmin vioittuneet puut kuolivat kesän kuluessa. Lievemmin vioittuneet puut olivat usein harvalehti- 


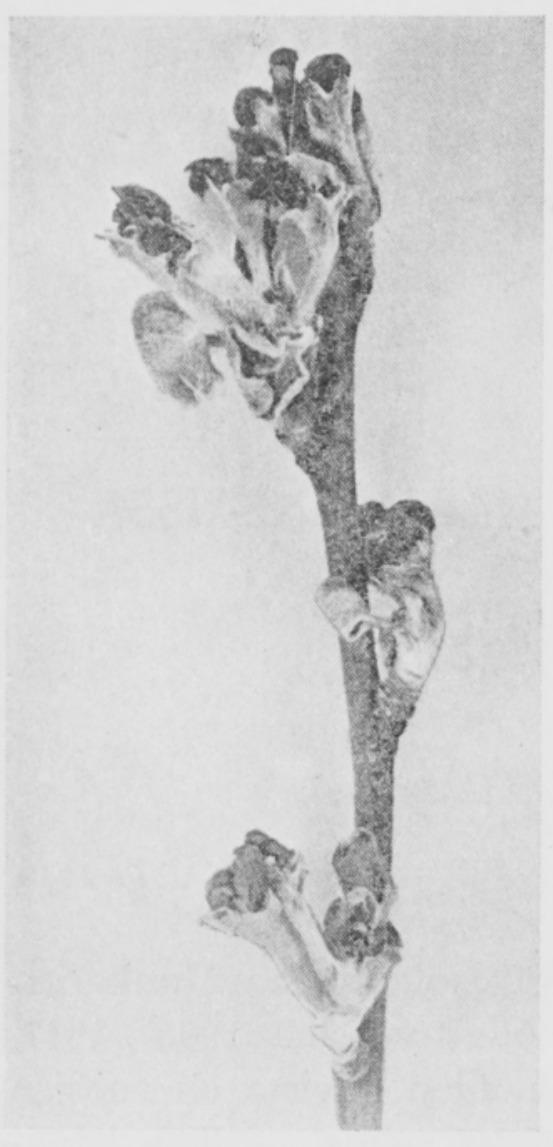

Kuva 1. Keväällä kuivunut Anisovka-puun oksa, jossa kukkasilmut jäivät aukeamatta. Orig. Fig. 1. Branch of an apple tree (Anisovka), dried up in spring, on which the buds did not break. siä ja lehdet olivat kooltaan tavallista pienempiä. Usein ruskettuivat lehtireunat, tai lehdet kuivuivat kokonaan. Puiden kasvukunnon heikentymisestä oli lisäksi seurauksena vuosiversojen kasvun tyrehtyminen $(2,6)$. Kesäkuun puolivälissä 1947 suorittamieni havaintojen mukaan oli lievästikin vioittuneissa puissa rungon ja oksien jälsikerros ruskehtava sekä puuaine normaalia kuivempi. Silmujen tyvessä oleva n.s. silmutyyny oli usein myös ruskettunut. Juuret sen sijaan olivat useimmiten valkeat ja mehevät. Ankarasti vioittuneissa puissa, jotka jo keväällä näyttivät kuolleilta, olivat juuret ruskeat ja vetiset.

Herukka- ja karviaismarjapensaissa ilmenivät talven aiheuttamat vauriot siten, että lehtisilmut puhkesivat tavallista hitaammin. Kesän kuluessa kuivuivat vaurioituneissa versoissa lehdet, kukat ja marjanraakileet äkkiä, ilman havaittavaa syytä. Muutamien versojen näin kuoltua saattoi muu osa pensasta kasvaa normaalisti. Pahemmin vioittuneet pensaat kuolivat kesän kuluessa kokonaan. Versojen kuivumista todettiin vielä syyskesälläkin sellaisissa pensaissa, jotka näyttivät välttyneen tuholta. Vaurioituneet marjapensaat kasvattivat kesän kuluessa yleensä uusia versoja, sillä pensaiden juuret olivat nähtävästi säilyneet terveinä. Kuitenkin esiintyi tapauksia, jolloin uusia versoja ei kasvanut, ja lienevät pensaat tällöin olleet pahemmin vioittuneita.

Muissa puutarhakasveissa olivat talven aiheuttamat vauriot vähäiset. Paikotellen oli puutarhavadelmassa havaittu samanlaisia vahinkoja, kuin muissakin marjapensaissa. Puutarhamansikkaa oli pakkanen myös vioittanut aiheuttaen monin paikoin kasviyksilöiden kuolemista.

\section{Vioitukset eri osissa maata.}

Talven 1946-1947 aiheuttamat vioitukset olivat Maatalouskoelaitoksen kasvitautiosastolle saapuneiden tietojen mukaan ankarimmat maan parhaimmilla hedelmänviljelyseuduilla Varsinais-Suomessa ja Satakunnassa, jossa noin 75 - 80 $\%$ marjapensaista ja $10-75 \%$ hedelmäpuista on vahingoittunut tai tuhoutunut. Niinpä Maatalouskoelaitoksen puutarhaosastolla Piikkiössä oli kesäkuun puolivälissä suorittamani tarkastuksen mukaan hiekkamaan hedelmätarhassa $73 \%$ omenapuista epänormaalissa kasvukunnossa, savimaan hedelmätarhassa $65 \%$. Ahvenanmaalla ovat hedelmäpuut ilmoitusten mukaan vioittuneet yhtä pahoin kuin Varsinais-Suomessa.

Talven vahinkoja on havaittu runsaasti myös Uudellamaalla ja Hämeessä, jossa hedelmäpuut ovat vahingoittuneet, joskin lievemmin kuin Varsinais- 


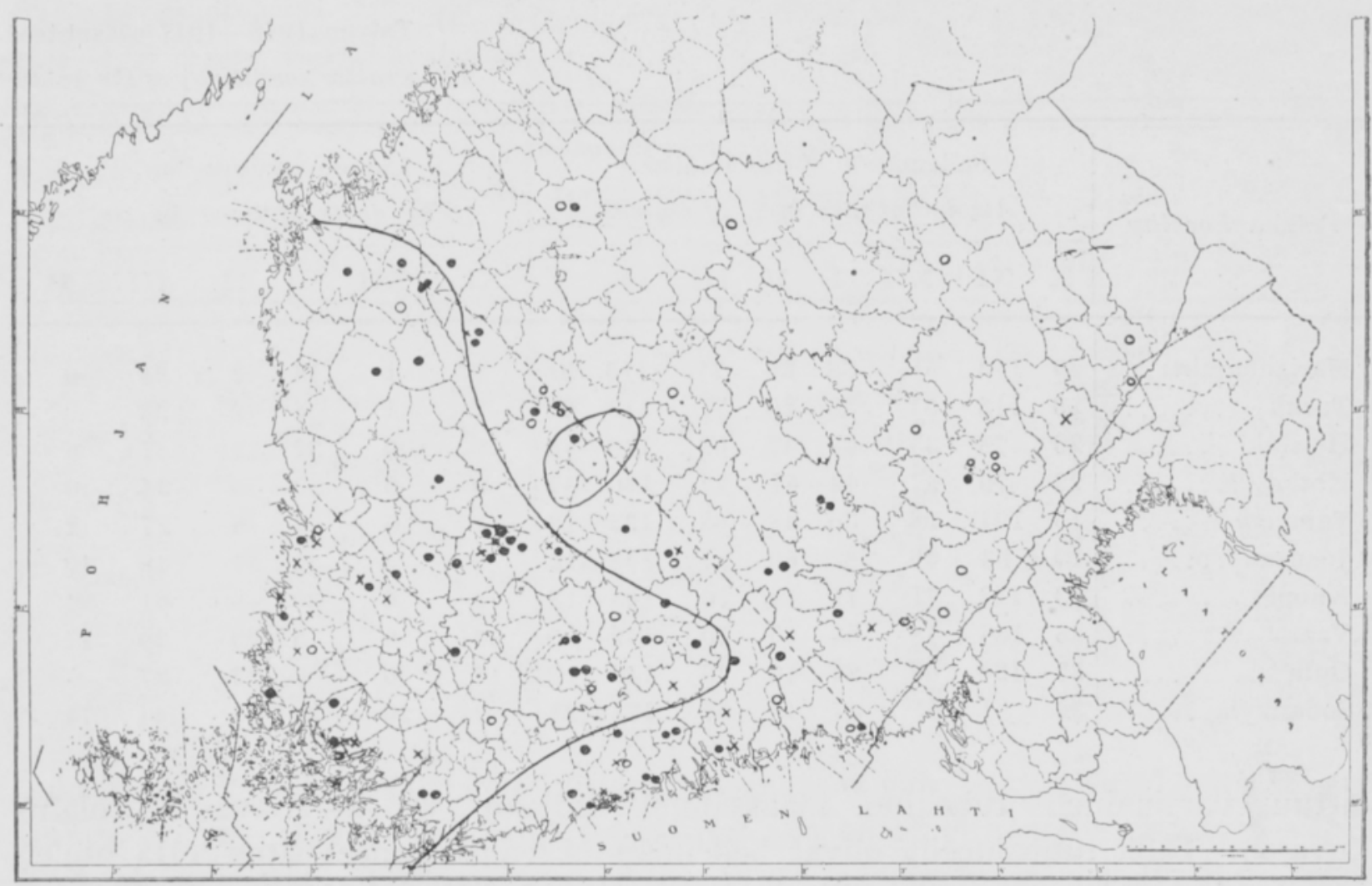

Kuva 2. Paikkakunnat, joilla talven vahinkoja on havaittu.

$x=$ omenapuiden ankara vioittuminen.

$\mathrm{O}=$ omenapuiden lievempi vioittuminen.

- = marjapensaiden vioittuminen.

Katkoviivalla piirretyn rajan länsipuolella on havaittu runsaasti tuhoja. Yhtenäinen viiva yhdistää paikkakunnat, joilla lumipeite 15. 3. 47 oli $30 \mathrm{sm}$ :n vahvuinen.

Fig 2. Localities, where winter injuries were seen.

$\times=$ severe damage to apple trees.

$\mathrm{O}=$ slight damage to apple trees.

- = damage to berry-bushes.

The broken line shows the limit of the damage-area. The connected line unites the areas, whose snow depth in March 15 th 1947 was $30 \mathrm{~cm}$.

Suomessa. Vioittuneiden marjapensaiden määrä tällä alueella vaihtelee $5-25 \%$. On merkillepantavaa, että Lounais-Hämeessä ja Länsi-Uudellamaalla ei sanottavia talven vahinkoja ole havaittu. Tekemilläni tarkastusmatkoilla olen myös todennut, että siellä hedelmäpuut ja marjapensaat ovat enimmäkseen normaalissa kasvukunnossa.

Kokemäenjoen laaksossa ja Tampereen ympäristössä on havaittu runsaasti vioituksia. Yksinomaan Tampereelta, Kangasalta ja Messukylästä on saatu ilmoituksia 20:stä puutarhasta, joissa vahingoittuneiden hedelmäpuiden ja marjapensaiden lukumäärä vaihtelee $10-20 \%$.

Etelä-Pohjanmaalta on tietoja hedelmäpuiden vahingoittumisesta saatu Vilppulasta, Haapamäeltä, Alavudelta ja Ilmajoelta; marjapensaiden vioittumista on havaittu 21:llä paikkakunnalla Tampereen ja Vaasan välisellä alueella.

Maatalouskoelaitoksen kasvitautiosastolle saapuneiden tietojen mukaan ra- 


\begin{tabular}{|c|c|c|c|c|c|c|c|c|c|c|c|c|c|c|}
\hline \multirow{2}{*}{ Paikka Localizy } & \multicolumn{8}{|c|}{$\begin{array}{c}\text { Sademäärä } \% \text { normaalista } \\
\text { Amount of rain in \% of normal. }\end{array}$} & \multicolumn{6}{|c|}{$\begin{array}{l}\text { Lumen syvyys sm. } \\
\text { The depth of snow in } \mathrm{cm} \text {. }\end{array}$} \\
\hline & $\mathrm{x}$ & $\mathrm{XI}$ & XII & I & II & III & IV & $\mathrm{V}$ & XI & XII & I & II & III & IV \\
\hline Marianhamina .. & 29 & 113 & 51 & 38 & 26 & 77 & 113 & 21 & 2 & 1 & 14 & 2 & 24 & 0 \\
\hline Turku $\ldots \ldots$. & 29 & 113 & 51 & 38 & 26 & 77 & 113 & 21 & 7 & 1 & 4 & 2 & 23 & 0 \\
\hline Helsinki $\quad \ldots \ldots$ & 26 & 78 & 35 & 47 & 42 & 99 & 148 & 65 & 0 & 0 & 32 & 18 & 47 & 0 \\
\hline Kotka ....... & 23 & 79 & 37 & 42 & 41 & 72 & 160 & 47 & 0 & 0 & 30 & - & 34 & 0 \\
\hline Tampere ..... & 16 & 104 & 38 & 50 & 48 & 88 & 132 & 18 & 1 & 0 & 13 & 8 & 27 & 2 \\
\hline Joensuu....... & 20 & 93 & 46 & 82 & 60 & 87 & 148 & 14 & 3 & 5 & 26 & 37 & 48 & 40 \\
\hline Kuopio ........ & 33 & 142 & 71 & 71 & 49 & 76 & 183 & 13 & 4 & 6 & 30 & - & 61 & 58 \\
\hline Vaasa $\ldots \ldots$. & 25 & 158 & 48 & 84 & 46 & 60 & 142 & 6 & 33 & 0 & 8 & 20 & 30 & 17 \\
\hline Oulu $\ldots \ldots \ldots$ & 33 & 130 & 60 & 84 & 46 & 35 & 159 & 10 & 17 & 0 & 6 & 22 & 27 & - \\
\hline Sodankylä...... & 32 & 81 & 65 & 47 & 43 & 67 & 175 & 33 & 2 & 26 & 33 & 43 & 44 & 74 \\
\hline
\end{tabular}

joittuu varsinainen tuhoalue maassamme linjaan Vaasa-Alavus-Virolahti (kuva 2). Tällä tuhoalueella olivat hedelmäpuut vaurioituneet siten, että niiden kasvukunto heikkeni, kasvu pysähtyi, tai puu kuoli kokonaan. Muista osista maata, mainitun linjan koillispuolelta on myös saatu tietoja omenapuiden vahingoittumisesta, mutta siellä ovat vain puiden vuosiversot tai nuoret, edellisenä syksynä istutetut puuntaimet kuolleet. Tietoja tällaisesta hedelmäpuiden vahingoittumisesta on tullut Lemiltä, Lappeenrannasta, Joutsenosta, Ruokolahdelta, Savonlinnan ympäristöstä, Rantasalmelta, Kiteeltä, Värtsilästä sekä Tuupovaảrasta. Sen lisäksi on vuosiversojen paleltumista havaittu Vesangalla, Kaavilla, Keiteleellä ja Perhossa. Näissä tapauksissa on kysymys erilaisesta vauriomuodosta, johon nähtävästi on ollut syynä pakkasen välitön kylmyysvaikutus. Marjapensaiden vioittumista on todettu Taavetissa, Mäntyharjussa, Mikkelissä, Kangasniemellä, Savonlinnassa sekä Perhossa. Edelläesitetyistä tiedoista päätellen on todennäköistä, että versojen ja nuorien taimien paleltumista on esiintynyt yleisesti koko KeskiSuomessa. Syynänäihin paleltumisilmiöihin on pidettävä lähinnä tammikuusta maaliskuuhun 1947 kestäneitä y h t ämittaisia ankaria pakkasia. Kun Lounais-Suomessa havaitut talven vahingot ilmenivät toisin, kuin Keski-Suomessa havaitut paleltumaviat, johtuvat ne muista syistä kuin pakkasen välittömästä kylmyysvaikutuksesta kasveihin.

\section{Vioitusten tarkastelu.}

Kuten edellä osoitettiin, on talven 1946-1947 aiheuttamia vaurioita hedelmäpuissa ja marjapensaissa havaittu pääasiassa alueella, jota koillisessa rajoittaa linja Vaasa-Alavus-Virolahti. Tämän linjan lounaispuolella ovat vioitukset paikoin ankarat, paikoin on kuitenkin alueita, joilla ei vioituksia ole havaittu. On selvää, että tietoja kaikilta tuhoseuduilta ei ole saatu, mutta neuvojien lähettämät tiedoi- 
eräillä havaintoasemilla.

1946-1947 at some observation stations.

\begin{tabular}{|c|c|c|c|c|c|c|}
\hline \multicolumn{7}{|c|}{$\begin{array}{l}\text { Kuukauden keskilämpö } \mathrm{C}^{\circ} \text {. } \\
\text { The mean temperature of the month in } \mathrm{C}^{\circ} \text {. }\end{array}$} \\
\hline XI & XII & I & II & III & IV & $\mathrm{V}$ \\
\hline 2,8 & 0,4 & $-4,5$ & $-10,3$ & $-6,7$ & 2,0 & 8,4 \\
\hline 0,9 & $-0,7$ & $-6,8$ & $-14,1$ & $-7,5$ & 2,5 & 10,2 \\
\hline 1,4 & $-0,6$ & $-6,6$ & $-12,8$ & $-6,2$ & 2,8 & 10,7 \\
\hline 0,5 & $-1,6$ & $-8,1$ & $-14,8$ & $-7,6$ & 1,5 & 9,3 \\
\hline$-0,3$ & $-2,0$ & $-8,4$ & $-13,7$ & $-7,9$ & 2,3 & 10,3 \\
\hline$-2,6$ & $-2,9$ & $-9,8$ & $-16,3$ & $-9,5$ & 1,7 & 8,9 \\
\hline$-3,0$ & $-3,7$ & $-10,6$ & $-16,1$ & $-9,2$ & $-0,1$ & 8,1 \\
\hline$-0,6$ & $-0,7$ & $-7,2$ & $-13,1$ & $-9,4$ & 1,3 & 8,8 \\
\hline$-3,8$ & $-1,3$ & $-9,0$ & $-15,8$ & $-12,0$ & 0,4 & 5,9 \\
\hline$-8,1$ & $-3,4$ & $-10,2$ & $-20,3$ & $-16,0$ & $-2,1$ & 5,0 \\
\hline
\end{tabular}

tukset sekä kesällä 1947 tekemäni tarkastusmatkat vahvistavat sitä käsitystä, että linjan Vaasa-Alavus_Virolahti luonaispuolella on alueita, joilla ei talven vahinkoja ole sattunut. Tiedossamme ei ole, mistä hedelmäpuiden säilyminen eräillä Lounais-Suomen seuduilla vuonna 1947 johtuu. Tämän seikan selvittämisellä olisi oma merkityksensä hedelmänviljelyllemme.

Lounais-Suomessa havaitut talven vahingot johtuvat muista syistä kuin pakkasen välittömästä kylmyysvaikutuksesta. Siten ilmenevää vaurioitumista hedelmäpuissa tiedetään tapahtuneen aikaisemminkin. EBERT (1) mainitsee omenapuiden kasvukunnon heikkenemisen pakkastalvien 1916-1917, 1918-1919 ja 1919-1920 jälkeen johtuvan ravitsemushäiriöistä sekä juurien vahingoittumisesta. Kasvun pysähtymistä hedelmäpuissa, varsinkin kirsikkapuissa esiintyi Saksassa myös vuonna 1928 (8). Syynä pidettiin tällöin ankaraa talvea sekä epäsuotuisia sääsuhteita seuraavana kesänä. Nyt sattunutta hedelmäpuiden vioittumista pitää Meurman (6) kuivumisilmiönä, joka johtui maan syvästä routaantumisesta sekä juurien osittaisesta vahingoittumisesta; nämä taas olivat seurauksena talven 1946 - 1947 epäedullisista sääsuhteista, varsinkin vähälumisuudesta.

Ylläolevassa taulukossa on esitetty numerotietoja talven 1946-1947 sääsuhteista eräillä havaintoasemilla (3). Hedelmäpuiden ja marjapensaiden vahingoittumiseen vaikuttavina säätekijöinä voidaan mainita seuraavat.

Syksyn 1946 sademäärä oli kaikkialla maassa, varsinkin lounaisosassa normaalia pienempi. Lokakuussa ja joulukuussa satoi Lounais-Suomessa ja Hämeessä noin kolmanneksen normaalivuosien sademäärästä näinä kuukausina. Maan vesivarastot olivat tämän vuoksi maan routaantuessa tavallista pienemmät. Tammi-helmikuussa 1947 oli lumipeite koko maassa normaalia ohuempi, linjan Perniö-Siuro-Merikarvia lounaispuolella oli lumetonta, linjan Parikkala-Haapamäki-Kokkola lounaispuolella oli lumipeitteen vahvuus vähemmän kuin $20 \mathrm{sm}$. Ankaria pakkassäitä oli maassamme tammikuun 10-15 ja 23-27 päivinä, koko helmikuun ajan 
sekä maaliskuun 22 päivään asti. Kun lumipeite Lounais-Suomessa koko ajan oli ohut (kuva 2) (7) routaantui maaperä tässä osassa maata normaalia syvempään. Kartassa sivulla 3 on yhtenäisellä viivalla yhdistetty ne paikkakunnat, joilla lumipeite 15. 3. 47 oli $30 \mathrm{sm}: \mathrm{n}$ vahvuinen. Viivan lounaispuolella olevilla alueilla lumipeite oli ohuempi kuin $30 \mathrm{sm}$. Näin vedetty linja seuraa likimain katkoviivalla piirrettyä tuhoalueen rajaa, joka kulkee Vaasan, Alavuden ja Virolahden kautta. Lumen vähyydestä johtuen on sulamisvesien vaikutuksen roudan sulamiseen sekä maan vesivaroihin täytynyt olla normaalia pienempi. Toukokuun sademäärä oli koko maassa erittäin vähäinen, pienin Vaasan, Hämeen, Mikkelin sekä Turun ja Porin lääneissä. Toukokuun keskilämpö oli $1-2,5$ astetta normaalia korkeampi ja Varsinais-Suomessa vuorokauden keskilämpö suuren osan kuukautta lähes $10^{\circ} \mathrm{C}$.

Lounais-Suomessa havaittu h e d e $1 \mathrm{~m}$ ä puiden j a m a r ja pensaiden vahingoittuminen johtui niiden maanpäällisten osien k u i v u m i s e s t a, joka pääasiassa tapahtui huhti-, touko- ja kesäkuussa. Tällöin aiheuttivat lämpimät ja aurinkoiset säät vilkkaan elintoiminnan kasveissa sekä voimakkaan haihtumisen näiden pintaosista. Kun maa oli talven vähälumisuudesta johtuen syvältä routaantunut eivätkä sulamisvedet ja sateet roudan sulamista keväällä riittävästi edistäneet, olivat kasvien juuret vielä kesäkuussa jäätyneessä maassa. Tästä syystä eivät kasvit saaneet haihduttamansa kosteuden tilalle tarpeeksi vettä. Kosteutta haihtui tällöin varsinkin puun pehmeistä pintaosista, kuoresta ja silmuista, joissa solukot kuivumisen vuoksi vahingoittuivat ja usein ruskettuivat. Lievästi vioittuneissa puissa olivat juuret terveen näköiset ja todennäköisesti ottivat kesän kuluessa normaalisti vettä. Kun kuoren johtosolukot olivat kuitenkin keväällä vahingoittuneet, ei nestevirtaus kesällä ollut normaali, josta johtunee versojen, lehtien ja hedelmien heikko kasvu. On mahdollista, että niiden puiden juuret, jotka jo keväällä kuolivat, olivat talven aikana ainakin osittain vahingoittuneet. Arvoitukseksi jää kysymys, miksi samassa tarhassa osa puita oli täysin terveitä, toisten samanikäisten ja samoissa olosuhteissa kasvaneiden puiden osoittaessa heikkoa kasvukuntoa tai kuolemisen oireita. Meurmanin (6) tekemien havaintojen mukaan ei puiden vahingoittuminen riippunut lajikkeen eikä perusrungon ominaisuuksista tai muista helposti selitettävistä syistä. Tähän kysymykseen eivät myöskään Maatalouskoelaitoksen kasvitautiosastolle saapuneet tiedot anna vastausta.

Hedelmän- ja marjanviljelyllemme näin koituneen vahingon suuruutta on vaikea tarkemmin määrittää. Saatuihin tietoihin perustuen voidaan arvioida noin $20-25 \%$ hedelmäsadostamme v. 1947 menneen ankaran talven vuoksi hukkaan. Menetyksen vastapainona olivat omenasadot siellä, missä kevätkuivumista ei ollut tapahtunut runsaat ja kuivan kesän ansiosta verraten terveet. Vielä ei vahinkojen lopullinen suuruus ole nähtävissä, koska on epätietoista, mihin suuntaan vuonna 1947 vahingoittuneiden puiden kehitys seuraavina vuosina kulkee. Jos seuraavat vuodet ovat hedelmänviljelylle suotuisat ja riittävän sateiset, voivat vahingot suureksi osaksi korjautua. Uuden tuhokauden uhatessa on viljelijän syytä auttaa hoidokkejaan kastelemalla niitä varsinkin keväällä kasvullisuuden herätessä eloon (5). 


\title{
S U M M A R Y.
}

\section{WINTER INJURY TO FRUIT TREES AND BERRY-BUSHES IN 1947,}

\author{
By \\ H. J. E. HÅRDH. \\ Agricultural Experiment Station, Department of Plant Pathology, Tikkurila.
}

Lately there have been injurious winters for the cultivation of fruit in Finland in 1915-1917, 1927-1929 and 1939-1942. The winter 1946-1947 again damaged fruit trees and the berry-bushes gooseberry, currant and raspberry; this damage was most severe in the best areas for cultivation of fruit in Varsinais-Suomi (Ab) and Satakunta (St). In these areas about $10-75 \%$ of the fruit trees and $75-80 \%$ of the berry-bushes were injured or died. Slight injuries generally have been noted in Uusimaa (N), Häme (Ta), in the Valley of Kokemäkiriver (St) and in the neighbourhood of Tampere (Ta). In southern Pohjanmaa (Oa) fruit trees and berry-bushes have been injured, too. The limit of the general injury-area is drawn through Vaasa (Oa), Alavus (Oa) and Virolahti (Ka). This limit closely follows the contour-line, to the west and southwest of which the depht of snow on March 15 th was 30 $\mathrm{cm}$ or less (fig. 2).

In the injury-area mentioned damage was such that the leaves expanded slowly in the spring, the flower buds, that appeared abundantly, opened slowly and the leaves and fruit were smaller than normally. In severely damaged trees the flower buds did not open, but dried up (fig. 1). In damaged trees, the cambium was generally brownish, the wood drier than normally, the roots, however, were generally white within and vigorous. The leaves of the berry-bushes expanded slowly in the spring; later in summer a many of the branches of damaged bushes died. These bushes generally grew new branches from their root.

The damage to fruit trees and berry-bushes was due to the drying of the parts above ground in the spring, when the warm and sunny weathers induced activity of the vital functions in the plants. The soil was, however, deeply frozen because of the thin winter snowcover and when the thaw waters and rainwaters in May, with a little amount of rain, did not melt the ice, the roots were still in June in the frozen soil and did not absorb enough water from the soil, which even apart from this was too dry, to make up the evaporated moisture. Then the soft surface parts of the trees, rind and buds, were damaged. In summer the roots may perhaps have absorbed a normal amount of water, but because of the damage to the vascular system in the rind the flowing of solutions in the summer was not normal, and the shoots, leaves and fruits grew weakly. The damage to fruit trees was neither due to properties of the variety and stock nor the age of trees $(6)$.

In the central parts of the country twigs of trees and sapling fruit trees were frozen because of the severe frost in winter.

It can be estimated that $20-25 \%$ of the fruit yield in Finland in 1947 was lost for the winter injuries.

\section{KIRJALLISUUS.}

(1) Ebert, W. 1920. Die Frostwirkung der letzten Jahre in ihrem Einfluss auf die Entwicklung der Obstbäume. Gartenwelt, 24, p. 478-480. Ref. Zeitschrift für Pflanzenkrankheiten, 31, p. 121, 1921.

(2) HÅrdh, H. J. E. 1947. Viime talven pakkasvioitukset hedelmäpuissa alkavat näkyä? Kasvinsuojelu-uutiset 1947, n:o 5, p. $7-8$.

(3) Ilmatieteellisen Keskuslaitoksen kuukausikatsaukset Suomen sääoloihin, 40, p. 9 -12 ja 41 , p. $1-5$.

(4) Lehtonen, Värnö 1946. Omenanviljely. Porvoo.

(5) —- 1947. Onko hedelmätarhoja nyt syksyllä ruvettava kastelemaan? Puutarha, 50, p. 403-406.

(6) Meurman, O. 1947. Viime talven vaurioista hedelmätarhoissamme. Puutarha, 59, p. $325-326$.

(7) Rossi, Vегкко 1947. Lumen syvyydestä ja lumipeitteen vesiarvosta 15. 3. 47. Ilmatieteellisen keskuslaitoksen Kuukausikatsaus Suomen sääoloihin, 41, p. 4.

(8) Wartenberg, Hans 1933. Kälte und Hitze als Todesursache der Pflanze und als Ursache von Pflanzenkrankheiten. P. Sorauer, Handbuch der Pflanzenkrankheiten I, 1, p. 475-592, 1933. 